\title{
Glycosylated Hemoglobin in Diabetic Foot and its Correlation with Clinical Variables in a North Indian Tertiary Care Hospital
}

\author{
Mohammad Zubair ${ }^{1 *}$, Abida Malik² and Jamal Ahmad ${ }^{1}$
}

${ }^{1}$ Rajiv Gandhi Centre for Diabetes and Endocrinology, Faculty of Medicine, J.N. Medical College, Aligarh Muslim University, Aligarh 202002, India

${ }^{2}$ Department of Microbiology, Faculty of Medicine, J.N. Medical College,, Aligarh Muslim University, Aligarh 202002, India

\begin{abstract}
$\mathrm{HbA1c}$ reflects glycemia over 2-3 months and is the standard measure used to monitor glycemia in diabetic patients, but studies have not shown an association of $\mathrm{HbA1c}$ with DFU. We hypothesized that elevated $\mathrm{HbA} 1 \mathrm{c}$ would be most associated with extremity of DFU/DFI. To test this hypothesis we conducted a prospective study of 161 DFU individuals treated at the R G Centre for Diabetes \& Endocrinology, AMU. $64.8 \%$ were males and the $37.0 \%$ had ulcer $>1$ month. The majority of ulcer was neuropathic $(50 \%)$ and amputation was done in $28.4 \%$. $\mathrm{HbA} 1 \mathrm{c}>6.5 \%$ were significantly associated with Wagner grades, UTG, BMI, retinopathy, nephropathy, hypertension, neuropathy and smoking. A significant correlation was found between UTG $(r=-0.219, p=0.005)$, ulcer duration $>1$ month $(r=-$ $0.233, p=0.002)$, BMI $(r=0.154, p=0.05)$, ESR $(r=-0.169, p=0.031)$, Neuropathy $(r=-0.007, p=0.048)$, nephropathy $(r=-$ $0.165, p=0.036)$, hypertension $(r=0.207, p=0.007)$, retinopathy $(r=0.167, p=0.037)$ and smoking $(r=0.164, p=0.034)$ with $\mathrm{HbA} 1 \mathrm{c}>6.5 \%$. The diabetic patients with $\mathrm{A} 1 \mathrm{c}>6.5 \%$ showed a high risk of ulcer development in their foot. $\mathrm{A}$ significant correlation was observed with the clinical variables (ulcer duration $>1$ month, BMI, ESR, Neuropathy, nephropathy, hypertension, retinopathy and smoking with $A 1 c>6.5 \%$ which is independent of concomitant infections in DFU patients.
\end{abstract}

Keywords: Diabetic foot ulcer; HbA1c; Correlation

\section{Introduction}

The increasing incidence of diabetes mellitus which represents a group of chronic diseases characterized by high levels of blood glucose resulting from defects in insulin action, production or both has become a major health concern worldwide. One of the most common complications of diabetes in the lower extremity is the diabetic foot ulcer. An estimated $15 \%$ of patients with diabetes develop a lower extremity ulcer during the course of their disease $[1,2]$. Diabetic foot is a complex and heterogeneous disorder that affects 1 out of 5 patients with diabetes at least once in his or her lifetime with relevant consequences both on lower limb survival and general morbidity [3]. According to the international consensus guidelines' protocols [4], such a complex pathology necessitates the participation of a multidisciplinary team, including the diabetologist, the podiatrist, the vascular surgeon, the radiologist, and the infectious disease specialist, to manage and address all the various aspects and presentations of the pathology. Only about half of patients actually notice the lesion themselves, with the majority occurring on the digits [5]. Ill-fitting footwear frequently contributes to foot ulceration [6,7]. Inadequate shoe fitting cannot be felt in those patients with sensory neuropathy. Ulcers can form because of tight-fitting shoes causing constant pressure. However, loose shoes also cause ulcers, as a result of friction [8]. Neuropathy is a major contributing risk factor for foot ulcers and can involve both somatic and autonomic fibres. The myelinated (A-type) sensory fibres are associated with proprioception, sensation of light touch, pressure, and vibration, and motor innervations of the muscle spindles. Neuropathy of the A-type nerve fibre results in ataxic gait and intrinsic weakness of the foot muscles. Neuropathy of the C-type sensory fibres is the loss of protective sensation; it results in the loss of pain threshold with prolonged and increased shear forces and repeated trauma. In addition, loss of protective sensation due to peripheral neuropathy is the most common cause of ulceration. The HbAlc has several advantages to the FPG, including greater convenience, since fasting is not required; evidence to suggest greater pre-analytical stability; and less day-to-day perturbations during periods of stress and illness [9]. Blood glucose levels are clearly a major determinant of $\mathrm{HbA} 1 \mathrm{c}$ levels, which ultimately shows the diabetes control for the past 2 months. It has been mentioned in the past clinical trials that uncontrolled diabetes or elevated $\mathrm{HbAlc}$ levels are associated with the development of retinopathy and as well as other complications [10]. On the basis of research literature mentioned above, the current study was designed to find out the association between $\mathrm{HbAlc} \&$ diabetic foot in North Indian patients.

\section{Materials and Methods}

The study was a prospective cohart hospital based. We recruited 162 diabetic subjects with foot ulceration (group A) hospitalized between 2009 and 2012 at the Rajiv Gandhi Centre for Diabetes and Endocrinology, of Jawaharlal Nehru Medical College Hospital, Aligarh Muslim University, Aligarh. India. We also recruited 162 diabetic patients without foot ulceration (group B) admitted for other causes between 2009 and 2012. All patients gave informed consent to take part in this study. Foot ulcer was defined as a full-thickness skin defect that required $\geq 14$ days for healing [11]. Every subject with diabetic foot was matched for age ( \pm 3 years), sex, and BMI. Patients with inflammatory or infectious diseases, autoimmune and rheumatic diseases, cancer, haematological diseases and those who were under treatment with anti-inflammatory drugs, pregnant and lactating female

*Corresponding author: Mohammad Zubair, Rajiv Gandhi Centre for Diabetes and Endocrinology, Faculty of Medicine, J.N. Medical College, Aligarh Muslim University, Aligarh 202002, India, Tel: 0091-9410200162; E-mail: mohammad_zubair@yahoo.co.in

Received May 07, 2015; Accepted May 28, 2015; Published June 03, 2015

Citation: Zubair M, Malik A, Ahmad J (2015) Glycosylated Hemoglobin in Diabetic Foot and its Correlation with Clinical Variables in a North Indian Tertiary Care Hospital. J Diabetes Metab 6: 571. doi:10.4172/2155-6156.1000571

Copyright: ( 2015 Zubair M, et al. This is an open-access article distributed under the terms of the Creative Commons Attribution License, which permits unrestricted use, distribution, and reproduction in any medium, provided the original author and source are credited. 
patients were excluded. We also excluded patients with recent venous thromboembolism.

A detailed history and physical examination was carried out for every subject. Age, Sex, anthropometric measurements (body mass index), duration of diabetes, glycemic control prior to and during the hospital stay, lipid profile, presence of retinopathy, nephropathy (creatinine $>1.5 \mathrm{mg} \%$ or presence of albuminuria), neuropathy (absence of perception of the Semmes-Weinstein monofilament at 2 of 10 standard planter sites on either foot), peripheral vascular disease (ischaemic symptoms and intermittent claudication of rest pain, with or without absence of pedal pulses or posterior tibial pulses). The anklebrachial index $(\mathrm{ABI})$ was calculated as the ratio of the ankle systolic blood pressure (defined as the higher of the dorsalis pedis or posterial tibialis measurement,) divided by the higher brachial systolic pressure. Subject was classified as having PAD when they had an ABI $\leq 0.9$ and/ or when they had undergone a peripheral arterial bypass or amputation [8]. ADA criteria for hypertension was used (systolic blood pressure $\geq 140 \mathrm{~mm} \mathrm{Hg}$ and/or diastolic blood pressure $\geq 90 \mathrm{~mm} \mathrm{Hg}$ in subjects who are not taking antihypertensive medication or antihypertensive treatment yet present on admission). Hypercholesterolemia was defined as total serum cholesterol $\geq 150 \mathrm{mg} / \mathrm{dL}$ and hypertriglyceridemia as total serum triglyceride $\geq 200 \mathrm{mg} / \mathrm{dL}$ on the basis of ADA-2010 criteria [12]. Coronary artery disease was determined on the basis of history of physician-diagnosed angina, myocardial infarction, or any previous revascularization procedure assessed by questionnaire. Cerebrovascular disease (TIA/ischaemic stroke) was assessed by history, specific neurological examination executed by specialists, and hospitalized or radiological (brain computed tomography or brain magnetic resonance) records of definitive TIA or stroke. All patients had blood pressure, serum glucose, creatinine, serum cholesterol levels, serum triglyceride levels, and urinary albumin excretion (UAE) values measured on first day of admission to the hospital. Duration of ulcer, site, and size of ulcer, history of smoking, history of previous amputation and clinical outcome were noted in every patient. Clinical assessment for signs of infection (swelling, exudates, surrounding cellulitis, odor, tissue necrosis, crepitation and pyrexia) was made by one researcher classifying the ulcers and determining the presence of clinical signs of infection. Ulcer size was determined by multiplying the longest and the widest diameters and expressed in centimetres square. The wound was graded and staged at the time of hospitalization according to the University of Texas Wound classification system as grade 1 (superficial wound, not involving, tendon, capsule or bone), grade 2 (wound penetrating to tendon or capsule) and grade 3 (wound penetrating bone or joint). Grade 0 patients (pre- or post-ulcerative site that has healed) were excluded from the study. Diagnosis of extension to the bone was made in majority of patients by probing with a sterile steel probe. In the absence of sinus tract or an exposed bone, a standard radiograph showing signs of osteomyelitis in the bone was considered definitive and later on MRI was done to confirm the osteomyelitis in suspected patients. Amputation was defined as the complete loss in the transverse anatomical plane of any part of the lower limb [13].

\section{Sample collection and determination of HbAlc}

Blood samples were collected for the clinical investigations, between 8 am to 10 am after an overnight fast of 10-12 hours for all the routine investigation. Blood samples were collected:-

- In EDTA Na vials for $\mathrm{HbA}_{1} \mathrm{c}$,

o In sodium fluoride vials for plasma glucose,

o In plain vials for serum lipids and lipoproteins.

\section{Glycohaemoglobin [HbA1c]}

The D-10 Hemoglobin A1c Program utilizes principles of ionexchange high-performance liquid chromatography (HPLC). The assay procedure was followed as per directives of the kit, Bio-Rad Laboratories Inc., Hercules, California, USA.

\section{Statistical methodology}

The results were analysed using the SigmaPlot Version 11.1 program. The Shapiro-Wilk test was used to evaluate normality of variables. The differences between the groups were calculated with Student $t$ or the nonparametric U-Mann-Whitney tests. Results are expressed as median (lower Quartile $\leftrightarrow$ upper Quartile) for continuous variables and percentages for categorical data, with $\mathrm{P}<0.05$ considered significant. A logistic forward regression analysis, multiple linear regression and one way analysis was used to assess the association between all clinical variables and $\mathrm{HbA} 1 \mathrm{c} \%$ that independently predicted foot ulcer development with a $\mathrm{P}<0.05$. Risk for ulcer development was also estimated by odds ratio (OR) and risk ratio (RR) with $95 \%$ confidence intervals (CIs) that independently predict the foot ulcer.

\section{Results}

Baseline characteristic of subjects with diabetic foot in comparison with subjects without diabetic foot are given in Table 1. In group A, $82.7 \%$ of subjects had T2DM, while in group B T2DM was present in $90.1 \%$ of subjects. Regarding the duration of diabetes, $68.6 \%$ of subjects in group A vs $75.7 \%$ of subjects in group B could be diabetic by $>10$ years; the $31.4 \%$ vs $24.0 \%$ for $<10$ years in respective groups. Subjects in group A also presented, in comparison with those in group $\mathrm{B}$, increased mean \pm sd levels of HbA1c \% [9.6 $\pm 2.03 \%$ vs $7.9 \pm 0.86]$, serum creatinine $(\mathrm{mg} / \mathrm{dl})[1.24 \pm 0.56$ vs $1.11 \pm 0.52], \mathrm{LDL}-\mathrm{C}(\mathrm{mg} / \mathrm{dl})$ [75.89 \pm 18.34 vs $104.38 \pm 30.1]$, HDL-C $(\mathrm{mg} / \mathrm{dl})$ [34.6 \pm 3.34 vs 44.3 \pm 7.7], Total cholesterol (mg/dl) [136.93 \pm 13.7 vs $181.9 \pm 32.3]$, and triglycerides $(\mathrm{mg} / \mathrm{dl})[95.6 \pm 21.7$ vs $157.0 \pm 83.1]$ (Table 1$)$. The values of HbA1c and blood glucose levels in Group A and Group B at the time of admission and discharge were shown in Figures 1 and 2, which shows improvement in the hospital stay in both group A \& group B also.

\section{Univariate analysis}

In a univariate analysis $\mathrm{OR}$ and $\mathrm{RR}$ were calculated between Group A and Group B patients in which HbAlc were calculated. The predictive factor that were associated with predicting the foot ulcer were summarized in Table 2 . The significant factors that were most likely to have an association in prediction foot ulcer were HDL-C $(<40 \mathrm{mg} / \mathrm{dl})$ [OR1.188(1.12-3.15); RR 1.61(1.09-2.38); p=0.02], LDL-C (>100 mg/ dl) [OR 1.96(126-3.04); RR 1.40(1.11-1.75); p=0.003], Triglycerides $(>200 \mathrm{mg} / \mathrm{dl})$ [OR 1.86(1.12-3.10); RR 1.59(1.08-2.34); p=0.021], Neuropathy [OR 2.50(1.58-3.96); RR 1.74(1.31-2.31); p=0.0001], Hypertension [OR 1.86(1.19-2.89); RR 1.37(1.09-1.72); $\mathrm{p}=0.007$ ], on OHA [OR 3.31(2.07-5.29); RR 2.07(1.53-2.78); $\mathrm{p}=0.006$ ] and smoking cessation [OR 2.57(1.64-4.05); RR 1.50(1.23-1.84); $\mathrm{p}=0.001$ ]. In chi square test, following were the risk factors that were most likely to have an association in prediction foot ulcer were HDL-C $(<40 \mathrm{mg} /$ dl) $[\mathrm{p}=0.014]$, LDL-C $(>100 \mathrm{mg} / \mathrm{dl}) \mathrm{p}=0.007]$, Triglycerides $(>200$ $\mathrm{mg} / \mathrm{dl})[\mathrm{p}=0.015]$, Neuropathy $[\mathrm{p}<0.0001]$, Retinopathy $[\mathrm{p}<0.001]$, Hypertension $[\mathrm{p}=0.005]$, on OHA $[\mathrm{p}<0.0001]$ and smoking cessation $[\mathrm{p}<0.001]$.

\section{Multivariate analysis}

On multivariate analysis, the factors which showed a positive 
Citation: Zubair M, Malik A, Ahmad J (2015) Glycosylated Hemoglobin in Diabetic Foot and its Correlation with Clinical Variables in a North Indian Tertiary Care Hospital. J Diabetes Metab 6: 571. doi:10.4172/2155-6156.1000571

Page 3 of 6

\begin{tabular}{|c|c|c|c|}
\hline Factors & $\begin{array}{l}\text { Group A } \\
\text { Patients with Ulcer } \\
162\end{array}$ & $\begin{array}{l}\text { Group B } \\
\text { Patients without } \\
\text { ulcer } \\
162\end{array}$ & $P$ value \\
\hline Age (years) & $46.29 \pm 13.19$ & $47.10 \pm 12.13$ & NS \\
\hline T2DM/T1DM & $134(82.7) / 28(17.28)$ & $146(90.1) / 16(9.8)$ & NS \\
\hline Male/Female & $103(63.5) / 59(36.4)$ & $102(62.9) / 58(37.0)$ & NS \\
\hline \multicolumn{4}{|l|}{ Duration of Diabetes } \\
\hline$<10$ yrs & $111(68.5)$ & $123(75.9)$ & 0.065 \\
\hline$>10$ yrs & $51(31.4)$ & $39(24.0)$ & 0.048 \\
\hline Smoking (Yes/No) & $110(87.6) / 52(32.0)$ & $73(45.0) / 89(54.9)$ & 0.005 \\
\hline BMI (kg/sqmt) & $24.84 \pm 4.54$ & $24.03 \pm 4.23$ & $<0.001$ \\
\hline$<18.5$ & $4(2.4)$ & $12(7.4)$ & \\
\hline $18.5-22.9$ & $63(38.8)$ & $67(41.3)$ & \\
\hline $23.0-24.9$ & $68(41.9)$ & $57(35.1)$ & \\
\hline$>24.9$ & $27(16.6)$ & $26(16.0)$ & \\
\hline Systolic BP (mmHG) & $130.46 \pm 18.32$ & $133.33 \pm 18.82$ & 0.172 \\
\hline Diastolic BP (mmHG) & $85.24 \pm 16.8$ & $86.34 \pm 11.36$ & 0.485 \\
\hline HbA1c (\%) & $9.6 \pm 2.03$ & $7.9 \pm 0.86$ & $<0.005$ \\
\hline Plasma creatinine (mg/dl) & $1.24 \pm 0.56$ & $1.11 \pm 0.52$ & 0.032 \\
\hline LDL-C (mg/dl) & $75.89 \pm 18.34$ & $104.38 \pm 30.1$ & $<0.001$ \\
\hline HDL-C (mg/dl) & $34.60 \pm 3.34$ & $44.30 \pm 7.7$ & $<0.005$ \\
\hline Total cholesterol (mg/dl) & $136.93 \pm 13.7$ & $181.9 \pm 32.3$ & $<0.005$ \\
\hline Triglycerides (mg/dl) & $95.96 \pm 21.7$ & $157.01 \pm 83.1$ & $<0.005$ \\
\hline Neuropathy & $82(50.6)$ & $47(29.0)$ & $<0.0001$ \\
\hline Retinopathy & $82(50.6)$ & $38(23.4)$ & $<0.0001$ \\
\hline Nephropathy & $72(54.4)$ & $31(19.13)$ & $<0.0001$ \\
\hline Hypertension & $92(56.7)$ & $67(41.3)$ & $<0.0001$ \\
\hline \multicolumn{4}{|l|}{ Therapy } \\
\hline Insulin & $62(38.2)$ & $93(57.4)$ & $<0.05$ \\
\hline $\mathrm{OHA}$ & $87(53.7)$ & $42(25.9)$ & $<0.005$ \\
\hline Both & $13(8.1)$ & $27(16.7)$ & $<0.005$ \\
\hline \multicolumn{4}{|l|}{ Grade of ulcer } \\
\hline Grade 1 & $48(29.6)$ & - & - \\
\hline Grade 2 & $94(58.0)$ & - & - \\
\hline Grade 3 & $20(12.3)$ & - & - \\
\hline \multicolumn{4}{|l|}{ Ulcer size } \\
\hline$<4 \mathrm{~cm}^{2}$ & $38(23.4)$ & - & - \\
\hline$>4 \mathrm{~cm}^{2}$ & $124(76.5)$ & - & - \\
\hline \multicolumn{4}{|l|}{ Bacterial infection type } \\
\hline superficial & $48(29.6)$ & - & - \\
\hline subcutaneous & $94(58.0)$ & - & - \\
\hline osteomyelitis & $20(12.3)$ & - & - \\
\hline Amputation & $46(28.3)$ & - & - \\
\hline
\end{tabular}

\section{Correlation analysis}

There was a perfectly positive correlation corrected for age between HbAlc and Foot ulcer were BMI $(>23 \mathrm{~kg} / \mathrm{sqmt})(\mathrm{r}=0.154, \mathrm{p}=0.050)$, Retinopathy ( $\mathrm{r}=0.167, \mathrm{p}=0.037)$, hypertension $(\mathrm{r}=0.207, \mathrm{p}=0.007)$, and smoking habit $(\mathrm{r}=0.164, \mathrm{p}=0.034)$. While week correlation were neuropathy $(\mathrm{r}=-0.007, \mathrm{p}=0.048)$, and nephroathy $(\mathrm{r}=-0.165, \mathrm{p}=0.036)$ Table 4.

\section{Discussion}

In this study, we have demonstrated diabetic individuals WITH/ WITHOUT foot ulcer seen at the RGCDE, AMU, Aligarh, only elevated HbAlc was significantly independently associated with duration of diabetes, BMI, cholesterol status, diabetic complication like neuropathy, nephropathy \& retinopathy, and those on OHA therapy of management. This relationship was stronger for the wounds located on the foot, which were insensate neuropathic wounds (approximately $60 \%$ of all wounds), when our analysis was restricted to these foot wounds, this association of $\mathrm{HbAlc}$ remained significant.

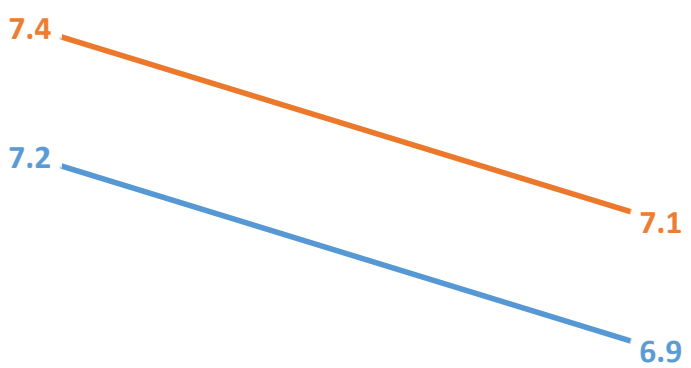

Admission

Discharge

$$
\text { - - Diabetic patients - -DFU patients }
$$

Figure 1: $\mathrm{HbA} 1 \mathrm{c} \%$ among diabetic patients with and without ulcer in foot at

association in predicting the foot ulcer by One way analysis were BMI $\left(>23 \mathrm{~kg} / \mathrm{m}^{2}\right)$, HDL-C $(<40 \mathrm{mg} / \mathrm{dl})$, LDL-C $(>100 \mathrm{mg} / \mathrm{dl})$, Total cholesterol $(>150 \mathrm{mg} / \mathrm{dl})$, Triglycerides $(>200 \mathrm{mg} / \mathrm{dl})$, Neuropathy, Retinopathy, Hypertension, Nephropathy and smoking habit (Table $3)$. Using multiple linear regression analysis, factors that predict the ulcer were BMI $\left(>23 \mathrm{~kg} / \mathrm{m}^{2}\right)$, HDL-C $(<40 \mathrm{mg} / \mathrm{dl})$, Neuropathy, Retinopathy, Hypertension, Nephropathy and smoking habit. In last analysis of multivariate analysis, the factors which show a positive risk factors by forward stepwise regression were Neuropathy, Retinopathy, Hypertension, Nephropathy and smoking habit.

the time of admission and discharge.

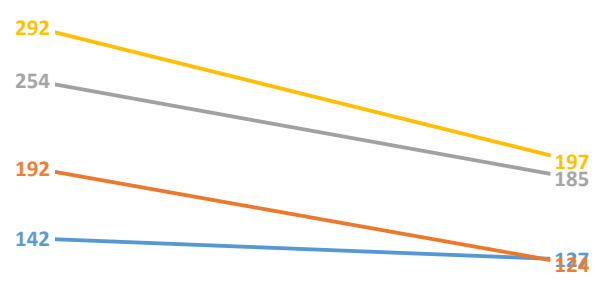

$\begin{array}{cc}\text { Admission } & \text { Discharge } \\ -- \text { Diabetic Male } \quad-\quad \text { Diabetic: Female } \quad-\quad \text { DFU: Male } \quad-\quad \text { DFU: Female }\end{array}$

Figure 2: Fasting and Postprandial blood glucose levels (mg/dl) among diabetic patients with and without ulcer in foot at the time of admission and discharge. 
Citation: Zubair M, Malik A, Ahmad J (2015) Glycosylated Hemoglobin in Diabetic Foot and its Correlation with Clinical Variables in a North Indian Tertiary Care Hospital. J Diabetes Metab 6: 571. doi:10.4172/2155-6156.1000571

Page 4 of 6

\begin{tabular}{|c|c|c|c|c|c|}
\hline \multirow[t]{2}{*}{ INDEPENDENT VARIABLE } & \multirow{2}{*}{$\begin{array}{c}\text { ODDS RATIO } \\
\text { OR(95\%Cl) }\end{array}$} & \multirow{2}{*}{$\begin{array}{c}\text { RISK RATIO } \\
R R(95 \% C l)\end{array}$} & \multirow[t]{2}{*}{ P-value } & \multicolumn{2}{|c|}{ CHI SQUARE TEST } \\
\hline & & & & YATES & $P$ \\
\hline AGE [>40 YRS] & $0.77(0.49-1.20)$ & $0.90(0.74-1.08)$ & 0.309 & 1.27 & 0.259 \\
\hline MALE/FEMALE & $1.02(0.65-1.61)$ & $1.00(0.85-1.19)$ & 0.99 & 0.01 & 0.92 \\
\hline $\mathrm{BMI}\left(>25 \mathrm{~kg} / \mathrm{mt}^{2}\right)$ & $1.34(0.87-2.09)$ & $1.16(0.93-1.44)$ & 0.219 & 1.8 & 0.179 \\
\hline Total cholesterol (>150 mg/dl) & $1.43(0.88-2.32)$ & $1.29(0.91-1.82)$ & 0.179 & 2.16 & 0.14 \\
\hline Triglycerides (>200 mg/dl) & $1.86(1.12-3.10)$ & $1.59(1.08-2.34)$ & 0.021 & 5.86 & 0.015 \\
\hline $\mathrm{HDL}-\mathrm{C}(<40 \mathrm{mg} / \mathrm{dl})$ & $1.88(1.12-3.15)$ & $1.61(1.09-2.38)$ & 0.020 & 5.94 & 0.014 \\
\hline LDL-C (>100 mg/dl) & $1.96(1.26-3.04)$ & $1.40(1.11-1.75)$ & 0.003 & 9.0 & 0.007 \\
\hline Neuropathy & $2.50(1.58-3.90)$ & $1.74(1.31-2.31)$ & 0.0001 & 15.78 & $<0.0001$ \\
\hline Retinopathy & $3.34(2.07-5.38)$ & $2.15(1.57-2.96)$ & 6.129 & 25.62 & $<0.0001$ \\
\hline Hypertension & $1.86(1.19-2.86)$ & $1.37(1.09-1.72)$ & 0.007 & 7.72 & 0.005 \\
\hline Nephropathy & $1.13(0.73-1.76)$ & $1.07(0.83-1.38)$ & 0.55 & 0.31 & 0.57 \\
\hline \multicolumn{6}{|l|}{ THERAPY } \\
\hline Insulin only & $0.46(0.24-0.71)$ & $0.66(0.52-0.84)$ & 0.0008 & 11.89 & 0.0005 \\
\hline $\mathrm{OHA}$ only & $3.31(2.07-5.29)$ & $2.07(1.53-2.78)$ & 0.006 & 26.08 & $<0.0001$ \\
\hline Both & $0.43(0.21-0.87)$ & $0.48(0.25-0.89)$ & 0.027 & 5.59 & 0.01 \\
\hline SGPT (IU/L) & $1.90(1.17-3.07)$ & $1.56(1.11-2.19)$ & 0.011 & 7.0 & 0.008 \\
\hline SGOT (IU/L & $1.72(1.11-2.68)$ & $1.30(1.05-1.61)$ & 0.019 & 5.98 & 0.014 \\
\hline TSP (gm \%) & $1.32(0.87-2.11)$ & $1.19(0.92-1.55)$ & 0.214 & 1.86 & 0.17 \\
\hline $\mathrm{SA}(\mathrm{gm} \%)$ & $1.91(0.76-1.84)$ & $1.08(0.88-1.31)$ & 0.502 & 0.61 & 0.434 \\
\hline Smoking & $2.57(1.64-4.05)$ & $1.50(1.23-1.84)$ & 0.001 & 4.39 & 0.001 \\
\hline
\end{tabular}

The following independent variable were considered for the model: HbA1c $(>6.9 \%)$, Total cholesterol (>150 mg/dl), Triglycerides ( $>200 \mathrm{mg} / \mathrm{dl})$, HDL-C (<40 mg/dl), LDL-C (>100 mg/dl), Neuropathy, Retinopathy, Hypertension, Smoking, SGOT/AST, serum glutamic oxaloacetic transaminase/aspartate transaminase; SGPT/AST, serum glutamate-pyruvate transaminase/aspartate transaminase, TSP, total serum protein. Only the variable that had a $p$ value $<0.05$ were considered in the final fitted model.

Table 2: Odds Ratio, Risk Ratio, To Study the Independent Variable Predicting Foot Ulcer In Diabetic Patients.

\begin{tabular}{|c|c|c|c|c|c|c|c|c|c|}
\hline \multirow[t]{2}{*}{ Independent variable } & \multicolumn{3}{|c|}{ One way analysis } & \multicolumn{3}{|c|}{$\begin{array}{l}\text { Multiple linear } \\
\text { regression }\end{array}$} & \multicolumn{3}{|c|}{ Forward step wise regression } \\
\hline & Total & Male & Female & Total & Male & Female & Total & Male & Female \\
\hline & $\mathrm{p}$ & $\mathrm{p}-$ & $\mathrm{p}$ & $\mathrm{p}$ & $p$ & $p$ & $\mathrm{p}$ & $p$ & $p$ \\
\hline Hospital stay $>1$ month & 0.05 & NS & NS & 0.029 & NS & NS & 0.022 & NS & NS \\
\hline Age $(y r s)$ & 0.05 & 0.05 & 0.05 & NS & NS & NS & NS & NS & NS \\
\hline Wagner Grades & 0.05 & 0.05 & 0.05 & $<0.001$ & $<0.001$ & 0.001 & $<0.001$ & 0.001 & 0.001 \\
\hline UTG & 0.05 & 0.05 & 0.05 & 0.025 & 0.05 & 0.045 & 0.025 & 0.032 & 0.045 \\
\hline Ulcer duration & 0.05 & 0.05 & 0.05 & NS & NS & NS & NS & NS & NS \\
\hline Size of ulcer (sq CM) & 0.05 & NS & NS & NS & NS & NS & NS & NS & NS \\
\hline BMI $\left(>25 \mathrm{~kg} / \mathrm{mt}^{2}\right)$ & 0.05 & NS & NS & 0.018 & 0.039 & NS & NS & NS & 0.05 \\
\hline$S$ creat & 0.05 & 0.05 & 0.05 & NS & NS & NS & NS & NS & NS \\
\hline ESR & 0.05 & 0.05 & 0.05 & NS & NS & 0.013 & NS & NS & NS \\
\hline SGPT (IU/L) & NS & NS & NS & $<0.001$ & 0.018 & 0.007 & NS & NS & NS \\
\hline SGOT (IU/L & NS & NS & NS & $<0.001$ & 0.013 & 0.045 & NS & NS & NS \\
\hline Alk Phosphate (IU/L) & 0.05 & 0.05 & 0.05 & $<0.001$ & 0.017 & 0.010 & NS & NS & NS \\
\hline TSP $(g m \%)$ & NS & NS & NS & 0.003 & NS & 0.023 & NS & NS & NS \\
\hline $\mathrm{SA}(\mathrm{gm} \%)$ & 0.05 & 0.05 & NS & 0.031 & NS & NS & NS & NS & NS \\
\hline SG (gm \%) & 0.05 & NS & NS & 0.016 & NS & NS & NS & NS & NS \\
\hline T-cholesterol (mg/dl) & 0.05 & 0.05 & 0.05 & NS & NS & NS & NS & NS & NS \\
\hline Triglycerides (mg/dl) & 0.05 & 0.05 & 0.05 & NS & NS & NS & NS & NS & NS \\
\hline HDL-C (mg/dl) & 0.05 & 0.05 & 0.05 & 0.029 & NS & NS & NS & NS & NS \\
\hline LDL-C (mg/dl) & 0.05 & 0.05 & 0.05 & NS & NS & NS & NS & NS & NS \\
\hline Neuropathy & 0.05 & 0.05 & 0.05 & $<0.001$ & 0.002 & $<0.001$ & 0.018 & 0.007 & $<0.001$ \\
\hline Retinopathy & 0.05 & 0.05 & 0.05 & 0.05 & 0.05 & 0.042 & 0.013 & 0.045 & 0.05 \\
\hline Hypertension & 0.05 & 0.05 & 0.05 & 0.025 & 0.045 & 0.028 & 0.045 & 0.028 & 0.025 \\
\hline Nephropathy & 0.05 & 0.05 & 0.05 & 0.035 & 0.001 & 0.050 & $<0.05$ & 0.012 & 0.035 \\
\hline Smoking & 0.05 & 0.05 & 0.05 & $<0.05$ & 0.012 & 0.016 & 0.024 & 0.05 & $<0.05$ \\
\hline
\end{tabular}

The following independent variable was considered for the model: HbA1c (>6.5 \%), Total cholesterol (>150 mg/dl), Triglycerides (>200 mg/dl), HDL-C (<40 mg/dl), LDL-C (>100 mg/dl), Neuropathy, Retinopathy, Hypertension, SGOT/AST, serum glutamic oxaloacetic transaminase/aspartate transaminase; SGPT/AST, serum glutamatepyruvate transaminase/aspartate transaminase, TSP, total serum protein, and Smoking. Only the variable that had a $p$ value $<0.05$ were considered in the final fitted model, NS; non-significant.

Table 3: Multiple Linear Regression Analysis, Forward Stepwise Regression Analysis and One Way Anova Analysis to study the Independent Variable Predicting Foot Ulcer in Diabetic Patients. 


\begin{tabular}{|c|c|c|c|c|c|c|}
\hline \multirow{2}{*}{ Independent Variable } & \multicolumn{2}{|c|}{ Total } & \multicolumn{2}{c|}{$\begin{array}{c}\text { Male } \\
\text { Patients }\end{array}$} & \multicolumn{2}{c|}{$\begin{array}{c}\text { Female } \\
\text { Patients }\end{array}$} \\
\hline & $\boldsymbol{r}$ & $\boldsymbol{p}$ & $\boldsymbol{r}$ & $\boldsymbol{p}$ & $\boldsymbol{r}$ & $\boldsymbol{p}$ \\
\hline Hospital stay $>1$ month & -0.033 & 0.677 & 0.031 & 0.749 & 0.116 & 0.397 \\
\hline Wagner Grades & 0.079 & 0.315 & -0.353 & 0.002 & -0.053 & 0.695 \\
\hline UTG & -0.219 & 0.005 & 0.150 & 0.126 & 0.300 & 0.024 \\
\hline Ulcer duration & -0.233 & 0.002 & -0.082 & 0.406 & 0.0003 & 0.998 \\
\hline Size of ulcer & -0.0375 & 0.636 & -0.026 & 0.789 & -0.045 & 0.742 \\
\hline BMI (>25kg/mt $\left.{ }^{2}\right)$ & 0.154 & 0.050 & 0.150 & 0.126 & 0.300 & 0.024 \\
\hline WBC & -0.145 & 0.067 & -0.153 & 0.122 & -0.165 & 0.222 \\
\hline S creat & -0.098 & 0.214 & 0.003 & 0.971 & 0.002 & 0.988 \\
\hline ESR & -0.169 & 0.031 & -0.188 & 0.055 & -0.095 & 0.485 \\
\hline Alk Phos & 0.090 & 0.256 & 0.042 & 0.663 & 0.323 & 0.015 \\
\hline Triglycerides & -0.018 & 0.814 & -0.076 & 0.441 & 0.294 & 0.027 \\
\hline HDL-C & 0.009 & 0.904 & -0.050 & 0.613 & 0.088 & 0.516 \\
\hline LDL-C & 0.013 & 0.864 & 0.035 & 0.719 & -0.216 & 0.109 \\
\hline Neuropathy & -0.007 & 0.048 & 0.234 & 0.002 & 0.207 & 0.007 \\
\hline Retinopathy & 0.167 & 0.037 & 0.155 & 0.048 & 0.141 & 0.072 \\
\hline Hypertension & 0.207 & 0.007 & 0.250 & 0.001 & 0.174 & 0.026 \\
\hline Nephropathy & -0.165 & 0.036 & 0.118 & 0.035 & 0.155 & 0.049 \\
\hline Smoking & 0.164 & 0.034 & 0.036 & 0.005 & 0.161 & 0.040 \\
\hline
\end{tabular}

The following independent variable was considered for the model: $\mathrm{HbA} 1 \mathrm{c}(>6.5$ $\%)$, Total cholesterol (>150 mg/dl), Triglycerides (>200 mg/dl), HDL-C (<40 mg/ $\mathrm{dl})$, LDL-C (>100 mg/dl), Neuropathy, Retinopathy, Hypertension and Smoking. Only the variable that had a $p$ value $<0.05$ were considered in the final fitted model.

Table 4: Correlation analysis between $\mathrm{HbA} 1 \mathrm{c}$ and laboratory and clinical variables in patients with diabetic foot.

The literature on age is also mixed, Apelqvist and Agardh [14] reported a higher risk of amputation with increasing age, but Ince et al. [15], Golinko et al. [16] and Margolis et al. [17] reported no association with age and the same was also reported in our previous study [18]. This study results are similar to [14] and our previous study [18] where positive association with cholesterol or white blood cell count between foot amputee patients and non-amputee patients. In addition, according to the obtained results, it is clear that as HbAlc levels are increasing and hence, there is a progressive loss of vibration sensations. For those patients in whom $\mathrm{HbAlc}$ levels are higher, they definitely have loss of vibration sensations. This reflects their poor glycaemic control at the time of examination or presentation. Further, it is clear that those patients, in whom high HbAlc levels have developed neuropathy, shows again reflecting poor glycaemic control. The associations between demographic, clinical, laboratory variables and healing in the literature are not consistent, our study is largely in agreement with existing reports where the majority of clinical data are not associated with wound healing per day. These findings can be correlated to the fact that diabetes mellitus being a metabolic disorder causes the altered protein and lipid metabolism and thereby abnormal granulation tissue formation. It can also be significantly supported by the findings of Goldin et al. [19] who indicated that increased glucose levels in the body end up in uncontrolled covalent bonding of aldose sugars to a protein or lipid without any normal glycosylation enzymes. The accumulation of these products called advanced glycation end product (AGEs) over the surface of cell membranes occurs on extracellular matrix proteins and alter the properties of matrix proteins such as collagen, vitronectin and laminin results in increased stiffness and increased synthesis of granulation tissue [19-22].

This relationship was also stronger among participants with peripheral artery disease. Our results suggest that HbAlc is an important clinical predictor of wound, particularly in those with neuropathic foot wounds and in those with peripheral artery disease. To our knowledge, a strong association between $\mathrm{HbAlc}$ and diabetic complications including biochemical parameters over time in a large clinic population of diabetic individuals is previously unreported. Previous studies have found either no association [14,17] or have reported a trend, but have had small sample size and did not statistically analyze data [23]. Previous studies have used need for amputation $[14,18]$ or total time to complete healing $[17,23]$ as the outcome of interest.

The most important aspect of this study was to determine the association between the diabetic complications i.e., the high risk foot and the development of the progressive retinopathy. According to Table 2, Odds ratio, Risk ration and Pearson chi square statistics, this association was found to be highly significant at the level of $\mathrm{p}$-value of $<0.001$. Similar results were also observed for hypertension, neuropathy, and patients on oral antidiabetic medications, LDL-C, HDL-C and smoking cessation except in a study reported from Bangladesh where the cholesterol, LDL and TG were higher in diabetic patients compared with DFU [24]. One of the important assessments from the present study is that, diabetic patients cannot well examine their feet daily because of the occurrence of retinopathy or visual loss, and need assistance of other persons at home. It should also be noted that visual impairment is one of the risk factors for the development of diabetic foot ulcers, because of associations and their coincidence in diabetes.

Accordingly, rise in $\mathrm{HbA1c}$, patients have developed nonproliferative and proliferative retinopathy, indicating severity of retinopathy with uncontrolled diabetes. But, those patients who were having average $\mathrm{HbAlc}$ levels under controlled or less; they are within normal limits or have not yet developed retinopathy, when examined in the current study. In other words, diabetic complications will occur if blood sugars remain high for long time, and may occur at any level of the disease process, but those patients whose HbAlc was higher, have definitely developed the chronic complications as has been shown by the results in the present study. In addition, by identifying high-risk patient and tailoring a total foot care prevention program accordingly, the incidences of ulceration and lower extremity amputations can be reduced $[25,26]$. The results of the present study clearly indicate the most important complications of diabetes (nephropathy, retinopathy, hypertension and neuropathy) finally leads to the Diabetic Foot Syndrome, which occur together as glycemic control worsens $[27,28]$. In other words, to prevent the complications, the blood sugars should be controlled to the target levels as recommended by American Diabetes Association and other associations and others as well. Lowering $\mathrm{HbA1C}$ to below or around $7 \%$ has been shown to reduce microvascular and neuropathic complications. Therefore, for microvascular disease prevention, the $\mathrm{HbA1C}$ goal for non-pregnant adults in general is $7 \%$ [12].

Further, $\mathrm{HbAlc}$ is now considered also a diagnostic tool, as has been recommended by American Diabetes Association in 2010 [10] because now its methodology is standardized. Nevertheless in the past and still now it has been a good tool for monitoring diabetes and its complications. It is easy to measure and gives reliable evidence for the past control of diabetes. In our study and data, we have used this tool and have related its association with other complications reported by others [28-30].

Summary, in this study, keeping HbAlc in acceptable range (by intensifying treatment, education and counselling) will prevent the complications and will have greater impact on reducing the burden and health cost at National as well as International levels. The patients with foot ulcers exhibit a specific and nonrandom upregulation of 
Citation: Zubair M, Malik A, Ahmad J (2015) Glycosylated Hemoglobin in Diabetic Foot and its Correlation with Clinical Variables in a North Indian Tertiary Care Hospital. J Diabetes Metab 6: 571. doi:10.4172/2155-6156.1000571

Page 6 of 6

HbAlc \% in diabetic foot compared with patients without ulcer. These associations were independent of multiple potential confounders and were mainly associated with severity of ulceration (different grades of ulcer using University of Texas system). Diabetic patients at risk for foot lesions must be educated about risk factors and the importance of foot care, including the need for self-inspection and surveillance, monitoring foot temperatures, appropriate daily foot hygiene, use of proper footwear, good diabetes control, and prompt recognition and optimal evidence based treatment of newly discovered lesions. This emphasizes the importance of diabetic educator and the foot care specialist nurse. Also there is a need for multidisciplinary team including the diabetologist, the podiatrist, the vascular surgeon, the radiologist, ophthalmologist and the infectious disease specialist for better management and care for diabetic patients.

\section{References}

1. Reiber GE (2001) Epidemiology of foot ulcers and amputations in the diabetic foot. In: Bowker JH, Pfeifer MA (Eds) The Diabetic Foot. St. Louis: Mosby 1332.

2. Reiber GE, Boyko EJ, Smith DG (1995) Lower extremity foot ulcers and amputations in diabetes. In: Harris MI, Cowie C, Stern MP, (Eds). Diabetes in America. (2ndedn), USA: NIH Publication 409-427.

3. Levin ME (1995) Preventing amputation in the patient with diabetes. Diabetes Care 18: 1383-1394.

4. Apelqvist J, Bakker K, van Houtum WH, Nabuurs-Franssen MH, Schaper NC (2000) International consensus and practical guidelines on the management and the prevention of the diabetic foot. International Working Group on the Diabetic Foot. Diabetes Metab Res Rev 16 Suppl 1: S84-92.

5. Macfarlane RM, Jeffcoate WJ (1997) Factors contributing to the presentation of diabetic foot ulcers. Diabet Med 14: 867-870.

6. Apelqvist J, Larsson J, Agardh CD (1990) The influence of external precipitating factors and peripheral neuropathy on the development and outcome of diabetic foot ulcers. J Diabet Complications 4: 21-25.

7. Manna I, Pradhan D, Ghosh S, Kar SK, Dhara P (2001) A comparative study of foot dimension between adult male and female and evaluation of foot hazards due to using of footwear. J Physiol Anthropol Appl Human Sci 20: 241-246.

8. Bloomgarden ZT (2001) American Diabetes Association 60th Scientific Sessions, 2000: the diabetic foot. Diabetes Care 24: 946-951.

9. Saudek CD, Herman WH, Sacks DB, Bergenstal RM, Edelman D, et al. (2008) A new look at screening and diagnosing diabetes mellitus. J Clin Endocrinol Metab 93: 2447-2453.

10. (1995) The relationship of glycemic exposure (HbA1c) to the risk of development and progression of retinopathy in the diabetes control and complications trial. Diabetes 44: 968-983.

11. Jeffcoate WJ, Game F, Cavanagh PR (2005) The role of proinflammatory cytokines in the cause of neuropathic osteoarthropathy (acute Charcot foot) in diabetes. Lancet 366: 2058-2061.

12. American Diabetes Association (2010) Standards of medical care in diabetes, position statement, Diabetes Care 33: S11-S61.

13. Zubair M, Malik A, Ahmad J (2012) Plasma adiponectin, IL-6, hsCRP, and TNF-Ît levels in subject with diabetic foot and their correlation with clinical variables in a North Indian tertiary care hospital. Indian J Endocrinol Metab 16: $769-776$

14. Apelqvist J, Agardh CD (1992) The association between clinical risk factors and outcome of diabetic foot ulcers. Diabetes Res Clin Pract 18: 43-53.

15. Golinko MS, Margolis DJ, Tal A, Hoffstad O, Boulton AJ, et al. (2009) Preliminary development of a diabetic foot ulcer database from a wound electronic medical record: a tool to decrease limb amputations. Wound Repair Regen 17: 657-665.

16. Ince P, Kendrick D, Game F, Jeffcoate W (2007) The association between baseline characteristics and the outcome of foot lesions in a UK population with diabetes. Diabet Med 24: 977-981.

17. Margolis DJ, Kantor J, Santanna J, Strom BL, Berlin JA (2000) Risk factors for delayed healing of neuropathic diabetic foot ulcers: a pooled analysis. Arch Dermatol 136: 1531-1535.

18. Zubair M, Malik A, Ahmad J (2012) Incidence, risk factors for amputation among patients with diabetic foot ulcer in a North Indian tertiary care hospital. Foot (Edinb) 22: 24-30

19. Goldin A, Beckman JA, Schmidt AM, Creager MA (2006) Advanced glycation end products: sparking the development of diabetic vascular injury. Circulation 114: 597-605.

20. Singh R, Barden A, Mori T, Beilin L (2001) Advanced glycation end-products: a review. Diabetologia 44: 129-146.

21. Obayashi K, Akamatsu H, Okano Y, Matsunaga K, Masaki H (2006) Exogenous nitric oxide enhances the synthesis of type I collagen and heat shock protein 47 by normal human dermal fibroblasts. J Dermatol Sci 41: 121-126.

22. Brownlee M1 (1995) Advanced protein glycosylation in diabetes and aging Annu Rev Med 46: 223-234.

23. Markuson M, Hanson D, Anderson J, Langemo D, Hunter S, et al. (2009) The relationship between hemoglobin $A(1 \mathrm{c})$ values and healing time for lower extremity ulcers in individuals with diabetes. Adv Skin Wound Care 22: 365372

24. Hasan CMM, Parial M, Islam M, Ahmad MNU, Kasru A (2013) Association of $\mathrm{HbA1c}$, Creatinine and Lipid Profile in Patients with Diabetic Foot Ulcer. MiddleEast Journal of Scientific Research 16: 1508-1511

25. Armstrong DG1, Harkless LB (1998) Outcomes of preventative care in a diabetic foot specialty clinic. J Foot Ankle Surg 37: 460-466.

26. Bild DE1, Selby JV, Sinnock P, Browner WS, Braveman P, et al. (1989) Lowerextremity amputation in people with diabetes. Epidemiology and prevention. Diabetes Care 12: 24-31

27. [No authors listed] (1998) Intensive blood-glucose control with sulphonylureas or insulin compared with conventional treatment and risk of complications in patients with type 2 diabetes (UKPDS 33). UK Prospective Diabetes Study (UKPDS) Group. Lancet 352: 837-853.

28. Diabetes Control and Complications Trial/Epidemiology of Diabetes Interventions and Complications Research Group [DCCT-2] (2000) Retinopathy and nephropathy in patients with type-1 diabetes four years after a trial of intensive therapy. N Engl J Med 342: 381-389.

29. (1993) The effect of intensive treatment of diabetes on the development and progression of long-term complications in insulin-dependent diabetes mellitus. The Diabetes Control and Complications Trial Research Group. N Engl J Med 329: 977-986.

30. International Expert Committee1 (2009) International Expert Committee report on the role of the A1C assay in the diagnosis of diabetes. Diabetes Care 32: 1327-1334. 